\title{
Commentary Surviving sepsis: a guide to the guidelines
} Jean-Louis Vincent ${ }^{1}$ and John C Marshall ${ }^{2}$

\author{
1Department of Intensive Care, Erasme Hospital, Université libre de Bruxelles, Route de Lennik 808, B-1070 Brussels, Belgium \\ 2Department of Surgery and Critical Care Medicine, St Michael's Hospital, Bond Wing 4-007, 30 Bond Street, Ontario, M5B 1W8 Canada
}

Corresponding author: Dr Jean-Louis Vincent, jlvincen@ulb.ac.be

Published: 30 June 2008

This article is online at http://ccforum.com/content/12/3/162

(c) 2008 BioMed Central Ltd

Critical Care 2008, 12:162 (doi:10.1186/cc6924)

\begin{abstract}
The revised Surviving Sepsis Campaign (SSC) guidelines for the management of severe sepsis and septic shock have recently been published. These guidelines represent the end product of an intense process and provide a template approach to the early resuscitation and support of patients with sepsis, based on a synthesis of evidence that has been shown to improve the outcome of the septic patient. The SSC guidelines arose from a recognition that care of the septic patient was suboptimal for at least three reasons. First, the entity of sepsis was frequently not diagnosed in a timely fashion, allowing the process to evolve into a life-threatening syndrome of major physiologic organ system dysfunction. Secondly, even when sepsis was recognized, the urgency of treatment was underappreciated - and so haemodynamic resuscitation was tentative, and the administration of effective antibiotic therapy was often delayed. Finally, treatment was often suboptimal, and failed to take advantage of emerging insights into optimal approaches to patient management. The revised guidelines are far from perfect, but they represent the best available synthesis of contemporary knowledge in this area and as such should be promoted.
\end{abstract}

After a promising conception, a controversial confinement, and a difficult labour and delivery, the revised Surviving Sepsis Campaign (SSC) guidelines for the management of severe sepsis and septic shock have been published [1]. The guidelines represent the end-product of an intense process involving 55 intensive care unit experts and 16 scientific societies (Table 1).

\section{The guidelines process}

Guidelines are the product of an explicit, systematic approach to the evaluation and synthesis of available information on a particular clinical topic. Their reliability depends on three factors: the extent to which all relevant evidence is sought for evaluation; the quality of the available evidence; and the rigour of the evaluation process used.

The SSC guidelines are based on systematic reviews of medical literature published since 1980. The guidelines are clearly selective, being shaped by implicit assumptions about what questions are considered important. Included studies were limited to those published in peer-reviewed journals, to minimize the risk of overinterpreting studies that had not undergone independent peer review.

A significant challenge to the guidelines process is the inherent limitations of the available literature. These limitations are particularly problematic in areas where norms of practice are well established - the use of antibiotics or source control for the treatment of infection, for example. Randomized trials of antibiotics versus placebo in septic shock or of surgical excision versus expectant therapy for necrotizing soft tissue infections have not been, and probably never will be, performed. Recommendations in these areas can therefore only be informed by expert opinion. Data from studies undertaken in patient populations other than sepsis patients (general intensive care unit patients or patients with acute respiratory distress syndrome, for example) were included if there was no compelling reason to assume that the conclusions could not be generalized.

The latest guidelines used the Grading of Recommendations, Assessment, Development, and Evaluation methodology [2], which assigns a measure of the strength of the recommendation based not only on the evidence, but also on factors such as cost, plausibility, toxicity, and clinician acceptance. This method provides a more nuanced synthesis of data and, in the current guidelines, the strength of recommendation was established through a formal voting process, in recognition of the fact that in many areas participants had divergent interpretations of the evidence.

\section{The guidelines product}

Guidelines are not a compilation of truths, but are a summary of what is accepted by the authors as the best available evidence at that time. Recommendations will therefore change as new information becomes available, and as the clinical course of the disease of interest alters. Similarly, 
Table 1

Evolution of the sepsis guidelines

\begin{tabular}{lcccl}
\hline & $\begin{array}{c}\text { Organizations } \\
\text { involved }\end{array}$ & $\begin{array}{c}\text { Number of } \\
\text { participants }\end{array}$ & Process & Publication \\
\hline First & 1 (ISF) & $9^{\mathrm{a}}$ & EBM A to E & Intensive Care Medicine supplement, 2001 \\
Second & $3($ ISF, ESICM, SCCM) & 24 & EBM A to E & Critical Care Medicine and Intensive Care Medicine, 2004 \\
Third & 16 & 55 & GRADE & Critical Care Medicine and Intensive Care Medicine, 2008
\end{tabular}

EBM, evidence-based medicine; ESICM, European Society of Intensive Care Medicine; GRADE, Grading of Recommendations, Assessment, Development, and Evaluation; ISF, International Sepsis Forum; SCCM, Society of Critical Care Medicine. ${ }^{a}$ Actually there were more participants since there were fellows or junior faculty involved. ${ }^{\mathrm{b}} \mathrm{A}$ number of other societies also participated.

guidelines are not rules and do not preclude the clinician's prerogative to make specific decisions in an individual patient that may be inconsistent with general recommendations. For example, targeting a specific arterial or central venous pressure level may not be appropriate for every patient. Finally, guidelines do not establish legal standards of practice any more than any other published compilation of data might, and a strong rating for any particular recommendation does not preclude further research.

\section{Are the guidelines credible?}

Controversy and disagreement is inherent to any human process of decision-making and consensus-building. The guidelines development process was explicit and democratic. Working groups were established in key areas, and developed specific recommendations following a critical review and discussion of the literature. Recommendations that engendered any controversy were submitted to the 55 participants who voted by secret ballot to obtain the final recommendation; a strong Grading of Recommendations, Assessment, Development, and Evaluation recommendation had to receive the support of at least $80 \%$ of the participants.

Transparency has always been a key principle of the SSC guidelines process. All participants' financial conflicts of interest have been disclosed in detail. Academic conflicts or interest arising from having been involved in work driving a recommendation were addressed by ensuring that working groups included participants on all sides of an issue, and by requiring a full vote on contentious questions. Finally, the industry had no input into the development of the guidelines, and meetings related to the most recent guidelines received no industry funding.

Some have argued that the campaign is simply advanced marketing for activated protein C [3]. That Eli Lilly are interested in promoting education in the field of sepsis because they have a product to treat sepsis is unquestionably true. But the multiple checks and balances outlined above prevent any direct influence in the guidelines content. While the consensus process included a number of proponents of activated protein $\mathrm{C}$, it also included some of activated protein
C's more vocal critics. If Eli Lilly's primary objective is to cast their drug in a favourable commercial light, they have shown questionable judgement in supporting the SSC, as the current recommendation for activated protein $\mathrm{C}$ use in sepsis is a weak one.

Sixteen societies have endorsed the guidelines, but two societies elected not to. The Australia and New Zealand Intensive Care Society was one of these, concluding that the guidelines do not represent current practice in Australasia, and that some of the recommendations are the subject of ongoing clinical trials. While strongly supporting the guidelines process, the Society worry that the guidelines might be used in local quality-improvement programmes, leading to imposition of practices that are inferior to current practices.

There is indeed a risk that overly simplistic application of guidelines may result in less sophisticated management. Quality-improvement programmes, however, generally seek evidence of a process rather than compliance with specific practices. Moreover, the purpose of this and other guidelines processes has never been to constrain those who provide exemplary care, but rather to raise global standards by providing guidance to nonexperts. Initial analyses of data from centres participating in the campaign do suggest that guideline compliance can be associated with improved outcomes [4].

\section{Conclusions}

Guidelines are a relatively recent innovation in critical care, and the SSC has accomplished some remarkable successes, even before its final efficacy is established. The SSC has brought together a diverse international group of clinicians, and has begun to open a creative dialogue between emergency physicians, intensivists, infectious disease specialists and surgeons. The campaign has generated evidence-based recommendations for the early management of patients with severe sepsis, achieving a measure of acceptance little short of remarkable. The campaign has provided momentum to an ongoing collaborative process to synthesize evidence from clinical trials into practice 
guidelines. The SSC has not only generated information, but has embraced a process to disseminate that information, and to measure the ultimate success of doing so. The campaign has raised the profile of one of the leading causes of premature death in the world.

The SSC guidelines were developed to aid the clinician in managing an enormously complex group of patients. The guidelines are imperfect, and will change as we learn more. But the guidelines also represent the best available synthesis of contemporary knowledge in this area, and for this reason we believe they must be promoted.

\section{Competing interests}

J-LV has consulted for Eli Lilly and received honoraria and grant support from the company. JCM is a member of the steering committee of the SSC; he receives honoraria as a paid member of the steering committee for the Eli Lillysponsored PROWESS Shock study, and has served as a paid consultant to other companies with a commercial interest in the development of diagnostics and therapies for severe sepsis and septic shock, including Eisai, BectonDickinson, Hutchinson Technologies, and Spectral Diagnostics, and currently serves on data monitoring committees for Leo Pharma and Artisan.

\section{References}

1. Dellinger RP, Levy MM, Carlet JM, Bion J, Parker MM, Jaeschke R, Reinhart K, Angus DC, Brun-Buisson C, Beale R, Calandra T, Dhainaut JF, Gerlach H, Harvey M, Marini JJ, Marshall J, Ranieri M, Ramsay G, Sevransky J, Thompson BT, Townsend S, Vender JS, Zimmerman JL, Vincent JL: Surviving Sepsis Campaign: international guidelines for management of severe sepsis and septic shock: 2008. Crit Care Med 2008, 36:296-327.

2. Guyatt G, Gutterman D, Baumann MH, Addrizzo-Harris D, Hylek EM, Phillips B, Raskob G, Lewis SZ, Schunemann H: Grading strength of recommendations and quality of evidence in clinical guidelines: report from an American College of Chest Physicians task force. Chest 2006, 129:174-181.

3. Eichacker PQ, Natanson C, Danner RL: Surviving sepsis - practice guidelines, marketing campaigns, and Eli Lilly. $N$ Engl J Med 2006, 355:1640-1642.

4. Ferrer R, Artigas A, Levy MM, Blanco J, Gonzalez-Diaz G, Garnacho-Montero J, Ibanez J, Palencia E, Quintana M, de la TorrePrados MV: Improvement in process of care and outcome after a multicenter severe sepsis educational program in Spain. JAMA 2008, 299:2294-2303. 